\title{
From Product End-of-Life Sustainable Considerations to Design Management
}

\author{
Natalia Duque Ciceri ${ }^{1}$, Marco Garetti ${ }^{1}$, and Severine Sperandio ${ }^{2}$ \\ ${ }^{1}$ Politecnico di Milano, Department of Management, Economics and Industrial Engineering, \\ Piazza Leonardo da Vinci 32, 20133 Milano, Italy \\ \{natalia.duque, marco.garetti\} apolimi.it \\ ${ }^{2}$ IMS, Department LAPS, University of Bordeaux \\ 351, cours de la Liberation, 33405 Talence cedex, France \\ severine.sperandio@u-bordeaux1.fr
}

\begin{abstract}
Better understanding of the current product End-of-life sustainable practices leads to important feedback for the design of more "sustainable" so called eco-products, by identifying the design improvements that reduce the impact of manufactured goods on the environment and society. In this paper, we propose a way to assess the impact on product design that ultimately helps on deciding the product characteristics required for a desired End-of-life (EOL) practice (i.e. reuse, recycle, remanufacture, etc). Categories and criticality scales of impacts of these practices on the product design stages are proposed. Then, a framework is proposed to provide designers with guidance on how to proceed towards taking into account the impact of the sustainable requirements.
\end{abstract}

Keywords: Product End of Life, Product Design, Sustainable Development.

\section{Introduction}

Currently, we are at one of the booms of a "green era" often connected with the term sustainability (perhaps one of the words with the most attempts to be conceptualized and misused nowadays). Though, sustainability has an environmental, social, and economic connotation, its achievement is a matter of practical implementations, with the objective being that of minimizing the impact on the environment and society. Our current model of industrial and economic growth has become (unfortunately) the most damaging for the environment and the ecosystem in which we live. This impact from industrial practices is seen in the form of waste (hazardous/solid), overuse of natural resources (materials and energy), overproduction, toxic release, water emissions among many others. Only in terms of Greenhouse Gas (GHG) emissions, for instance, the world sources institute reported in 2005 that energy-related and industrial processes account for $64.7 \%$ of GHG emissions world-wide ${ }^{1}$. With this at stake, companies and product manufacturers are being faced with great challenges in their industrial practices. The greater challenge is that often performance measures are

\footnotetext{
${ }^{1}$ The World Bank Data and Statistics http://siteresources.worldbank.org
} 
based on cost, quality and productivity. However, with the current "boom" more and more companies are voluntarily or required to consider sustainable practices.

The idea proposed in this paper is not to provide with ultimate solutions, but rather with a tool and an overall perspective. This tool is addressed mainly for designers when taking into account the "sustainable" considerations during the new product development process and transfer them to the different phases of design management. The focus of this work is in the considerations related to the End-of-Life (EOL) of the product: reuse, recycle, remanufacture or dispose (landfill or incineration) and their impact during product design. Categories of impacts are proposed, as well as, criticality scales associated to a decisional framework connecting the risk management and the strategic design planning processes. The paper is organized as follows: in Section 2, concepts and role of product lifecycle and EOL sustainable options are introduced; categories and criticality scales of impacts of sustainable considerations on the product design stages are proposed in Section 3; then, a framework to manage the design and to provide designers with guidance on how to proceed so as to take the impact of these requirements into account is provided. Some conclusion remarks and discussions are provided in the last section.

\section{Closing the Loop from End-of-Life to Beginning-of-Life}

This work deals with the strategic dimension of sustainable development within an industrial context, as the objectives are to understand how sustainable considerations influence the future product design stages. Indeed, rapid technological changes of these last years and the increasing competition have already led companies to modify their products development activities. Also, there are now several categories of "new" product introduction: completely new, repositioning, new product lines, core product revision, etc. For example, the paradigm of product platforms (i.e. a grouping of individual products sharing a common technology) permits to classify different categories of product developments. A strategy of products platform allows reducing pieces and components, costs relative to the design of products and investments necessary for new manufacturing processes. But how do sustainable considerations coming from other phases, such as the EOL, impact the beginning of the product lifecycle? How these sustainable strategies or requirements lead to changes in design stages? Figure 1 illustrates this graphically, while showing the entire product lifecycle and the activities related to the three main phases: from Beginning-of-Life (BOL), through Middle-of-Life (MOL) until End-of-Life (EOL).

The EOL phase starts at the point of disposal by a customer (consumer or business) and includes different end routes, ranging from reuse of the product without any structural changes (i.e. lifetime extension) [1]; remanufacturing where a discarded, non-functional, or traded-in product is restored to like-new condition [2]; recycling, which involves the collection and treatment of waste products for use as raw material in the manufacture of the same or a similar ones; incineration, where combustible wastes are burned and changed into gases (with or without energy recovery); dumping waste underground or landfill [3]; or else simply ends up in emission or leakage into the environment. 


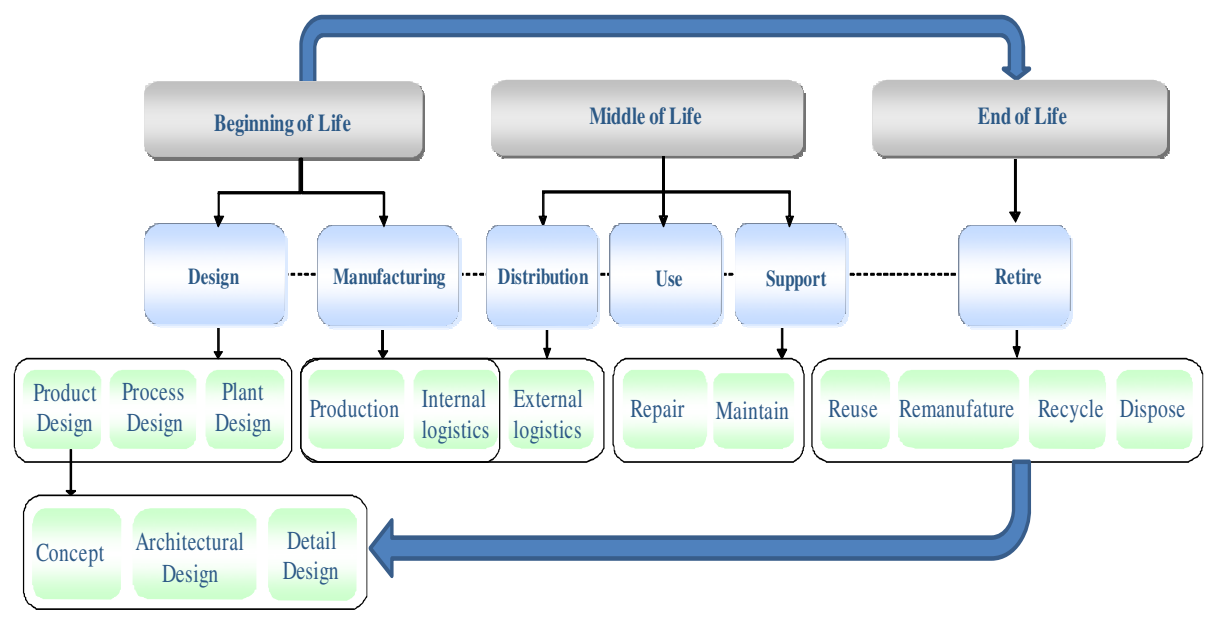

Fig. 1. Closing the loop from End-of-Life to Beginning-of-Life

It may be said that these options are presented in a traditional order of preference from an environmental point of view. However, this statement could be controversial among different EOL options and it varies from product to product and their application. This paper does not aim at evaluating how sustainable is a certain EOL practice or whether each one of them is sustainable or not. Therefore, for the purpose of this paper, the following assumptions are made on what the "sustainable" considerations are (i) defined by the single company or product manufacturer; (ii) encouraged either by internal influences (company-based) or external (suppliers, customers, government); (iii) implemented voluntarily or enforced (regulations, legislations). To illustrate such considerations that would require being transferred to the design stages, let us mention some examples:

- The regulated targets that the European Commission has established for different industries. For instance, WEEE (Waste of electrical and electronic equipment): mandatory collection targets equal to $65 \%$ of the average weight of electrical and electronic equipment placed on the market over the two previous years [4]. Similarly, with regulations such as ELV (End-of-Life Vehicles) [5]; RoHS (Restriction of use of certain Hazardous Substances) [6] among others.

- The increasing demand for eco-products by environmentally-conscious customers has forced companies to incorporate "green" initiatives to meet the demand of this growing market. For instance, recently a computer manufacturer has determined "reducing the environmental impact of their products within their design phase". For this, they redefine "the quantity of raw materials, as well as, the type and recyclability of materials used"2 to minimize waste at the end of a product's life. Besides these established visions and in the midst of improving their brand image, many companies have adopted such strategies as part of their "Corporate Social Responsibility"3 programs.

\footnotetext{
${ }^{2}$ http://www.apple.com/environment/design/

${ }^{3}$ A concept whereby companies voluntarily integrate social and environmental concerns in their business and the way they interact with stakeholders. [3].
} 
Behind each of these considerations, there are tremendous amount of decisions to be made by engineers, designers and other product/process decision-makers. How does each of these requirements affect the design of new products? How are they translated to the product functionality, customer needs, product architecture, marketability, reliability, performance, etc? Product development requires time. Very few products can be developed in less than one year, many require 3-5 years, and some may take as long as 10 years [7]. For the first example taken, each of these illustrated EU Directive requirements should be incorporated in today's product development plans for a company to stay in business in the upcoming years. The idea is to understand the present "sustainable" product to be able to predict the future "sustainable" product, and also identify changes to be introduced during the future design stages. For example, recycling and dismissal activities require and provide useful information on product components, materials and resources from/to the design and manufacturing stages. A visualization of this proposition is depicted in Figure 2:

- Along the X-axis there is time. The first aim is to understand "What is needed TODAY for "W" product to be in the market?" where product "W" is the product being analyzed. This is in relation with the different "requirements" (e.g. regulations, limited material resources, energy-related). The second aim is to understand "What type of EOL product-related information will be needed in the year " $X$ " for a sustainable product? Where year " $X$ " is any future year (e.g. 2015, 2020 , etc).

- Along the y-axis, the "sustainability level" which can be determined by: manufacturing regulations/legislations, energy and materials use, emissions reduction, hazardous materials use and waste, and labor standards, et cetera. To illustrate this level, we take the example of a regulation already into place in the automotive industry in Europe: $85 \%$ recycling/recovery rates in terms of weight by 2006 and $95 \%$ by 2015 .

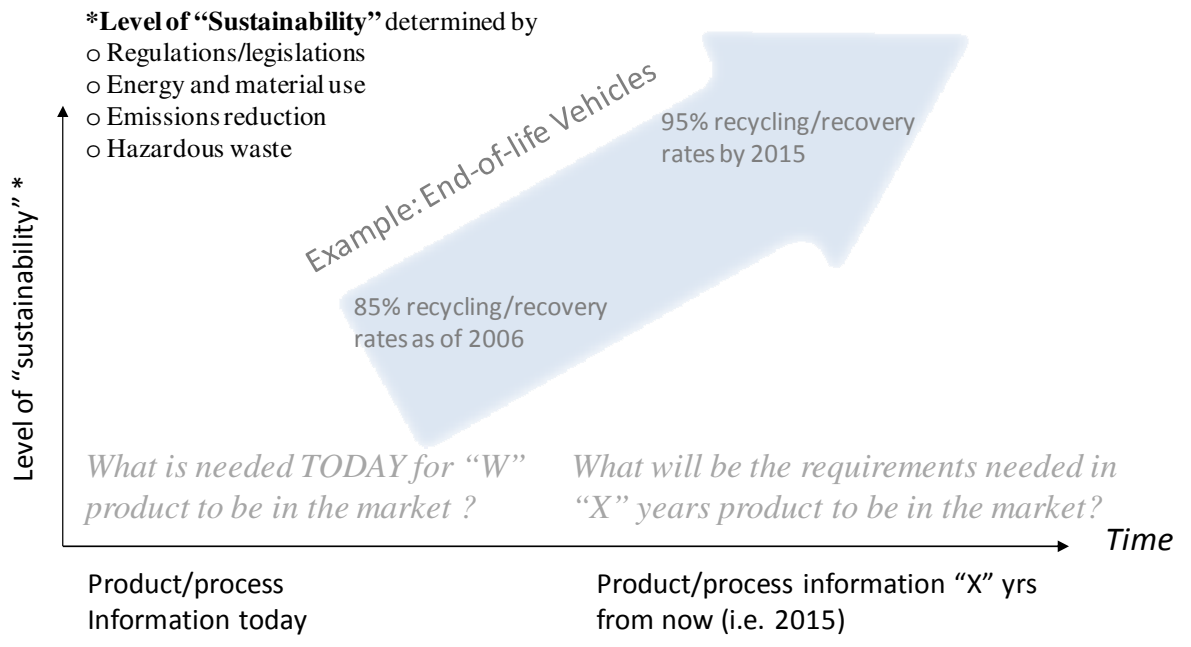

Fig. 2. Illustration of current and future sustainable requirements of products 


\section{Impact of EOL Sustainable Considerations in Product Design}

Many authors recognize that product design proceeds roughly (though not strictly) in stages or phases. Hence, models relative to design process intend to provide the designer with guidance on how to proceed from the recognition of a need to preliminary, abstract ideas on how that need could be met, and on to detailed, concrete solutions [8]. While no two design process models are exactly alike, they all seem to explicitly include a problem definition / information gathering / need recognition phase, a concept design phase, and a detail design phase. The majority also include a transition phase of some kind between concept and detail design. For example, Ulrich and Eppinger [7] define concept, system-level, and detail design phases of product development; Dym and Little [9] present concept, preliminary, and detailed design as key stages; Pahl and Beitz [10] identify concept design, embodiment or architectural design, and detail design as distinct design phases. In accordance with this last proposition, we decide to categorize the impact of an EOL sustainable practice strategy on the design process into four groups. Considering the different types of impact on the design process, we also establish four criticality classes associated with the actions to be carried out for the process to succeed:

- A "slight adjustment" leads to changes of resource capacities or operational constraints (e.g. constraints of precedence, temporal or cumulative constraints, etc). To take an example, some companies have opted for selling their brand remanufactured or reused guaranteed products, encouraging a good EOL sustainable option. This choice extends the life of the product and has a slight impact in the design phase (i.e. type of adjustments for this change are mostly operational-based).

- A "fair adjustment" entails modifications of capacities and / or competences of human and technical resources, legislated constraints, etc. For instance, reducing the amount of waste generated by products is correlated with the amount of materials used in each product. Say for example, the amount of plastic to make a water plastic

\begin{tabular}{|c|c|c|c|c|c|}
\hline Case & $\begin{array}{c}\text { Impact } \\
\text { category }\end{array}$ & Impact on the design process & $\begin{array}{c}\text { Criticality } \\
\text { classes }\end{array}$ & Level of risk & Decision \\
\hline Case 1 & $\begin{array}{c}\text { "Slight } \\
\text { adjustment" }\end{array}$ & $\begin{array}{c}\text { No impact on the architecture } \\
\text { of the current product }\end{array}$ & $\mathrm{C} 1$ & $\begin{array}{c}\text { Acceptable } \\
\text { in the present } \\
\text { state }\end{array}$ & $\begin{array}{l}\text { No action or modification at the functional } \\
\text { level. Follow-up, monitoring and review. } \\
\text { Risk assessment. Success probability of the } \\
\text { design closed to } 1\end{array}$ \\
\hline Case 2 & $\begin{array}{c}\text { "Fair } \\
\text { adjustment" }\end{array}$ & $\begin{array}{l}\text { Acts upon the organic or } \\
\text { architectural definition of the } \\
\text { current product }\end{array}$ & $\mathrm{C} 2$ & $\begin{array}{c}\text { Reasonable } \\
\text { under regular } \\
\text { control }\end{array}$ & $\begin{array}{c}\text { Modification at the organic level. Follow- } \\
\text { up, monitoring and review. Risk } \\
\text { assessment. A significant success } \\
\text { probability of the design. }\end{array}$ \\
\hline $\operatorname{case} 3$ & $\begin{array}{c}\text { "Large } \\
\text { adjustment" }\end{array}$ & $\begin{array}{c}\text { Requires strategic adjustments } \\
\text { of the current product impacting } \\
\text { its functional or conceptual } \\
\text { characteristics }\end{array}$ & $\mathrm{C} 3$ & $\begin{array}{l}\text { Difficult to } \\
\text { tolerate }\end{array}$ & $\begin{array}{l}\text { Modification at the functional level. } \\
\text { Follow-up, monitoring and review. Risk } \\
\text { assessment. A moderated success } \\
\text { probability of the design. }\end{array}$ \\
\hline Case 4 & $\begin{array}{c}\text { "Critical } \\
\text { adjustment" }\end{array}$ & $\begin{array}{l}\text { Makes the current product } \\
\text { obsolete. }\end{array}$ & $\mathrm{C} 4$ & Highest & $\begin{array}{l}\text { Change of strategy. Total reengineering of } \\
\text { the product. }\end{array}$ \\
\hline
\end{tabular}

Fig. 3. Impact of sustainable considerations on the design process (adopted from [11]) 
bottle is changed and to achieve this, the shape of the bottle has changed, then some technical changes have to occur during product and process design (i.e. architectural design and therefore different molds in the manufacturing phase).

- A "large adjustment" requires changes of the industrial activity, integration of new technologies, etc. Let us take the example of a cell phone, which its current recycling rate is roughly $11 \%$ [12]. Part of the reason why it is quite low is for the high material mixing content, which at the time of recycle, makes it rather difficult to separate these materials. If the recyclability desired is uplifted to $50 \%$ or more, depending on the changes designers decide to make to meet this target, it may require the integration of new materials or, for instance, reduction to only one type of plastic. If most of the functional components are kept, this change will compromise the conceptual design of the product (as many of its main characteristics are changed), but an acceptable amount of design content of the product can be kept as it is.

- In a "critical adjustment" it is necessary to remake all the design stages, including the problem definition / information gathering / need recognition phase. Let us say, the company is a nickel-cadmium rechargeable batteries manufacturer. Due to the poisonous nature of cadmium, which constitutes dangerous toxic waste, it is banned under the RoHS [5]. For this manufacturer, the redesign of the product is affected in all stages. This requires new technologies, materials and the design content of the previous product is unable to be kept.

Determination of these criticality classes, evidently, depends on specificities of each product or particular industry. Future "adjustments" due to sustainable objectives require an early diagnosis and management in the design process. To this purpose, a methodology is proposed by the authors, based on the framework illustrated in Figure 4, which will be described with a quick simple example through the steps.

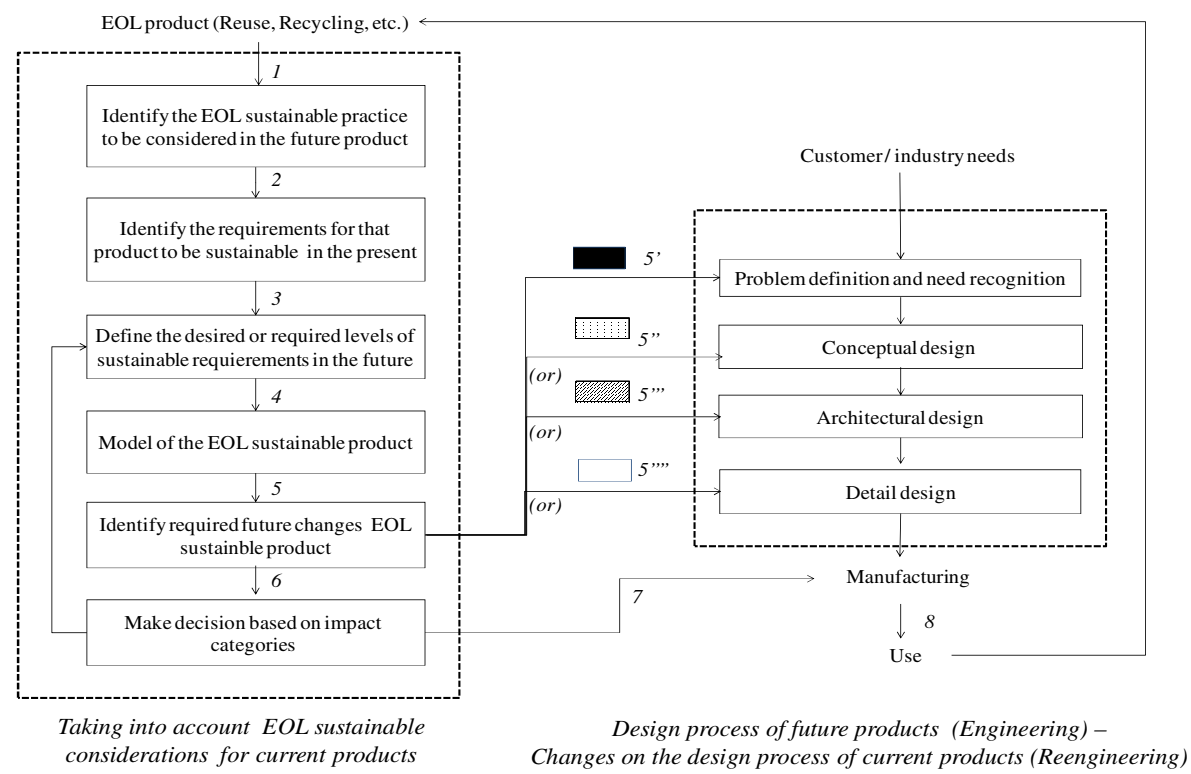

Fig. 4. Methodology: EOL sustainable considerations in the design process 
Let us consider the following EOL practice in the design of a TV product: $65 \%$ of the average weight of the TV is collected and at least $30 \%$ is recycled material and used as raw material in the manufacture of the same or a similar product. In this case, the present and future targets/levels of sustainability are given (step 2 and 3). Assuming that the product is manufactured or imported into Europe, where $65 \%$ of the average weight of a WEEE is collected [4]; we call this the present requirement. The future level is aimed at 30\% of the average weight of the TV being material recycled. For step 4, it is decided by the product designers that in order to meet this target, the current design can be modified in this way: steel parts will be made out of aluminum, which accounts for about $20 \%$ of the average product weight. The glass content is recycled along with the cooper accounting for $46 \%$ and $5 \%$ respectively. Assuming that at least half of these materials' content is actually recovered after the recycling process, which in the case of aluminum, cooper and glass is reasonable; then the resulting material recycled is about $35 \%$, resulting in the achievement of the desired target. Plastics and wood are not taken into consideration, given that their recycle fraction in current supply is less than $10 \%$ [13]. This constitutes the model of the EOL sustainable product design, summarized as follows:

Table 1. Model of the EOL sustainable product design

\begin{tabular}{lccc}
\hline $\begin{array}{c}\text { Billl of Materials - TV } \\
\text { (\% average weight) }\end{array}$ & $\begin{array}{c}\text { Current } \\
\text { Product* }\end{array}$ & EOL sustainable product & $\begin{array}{c}\text { Material } \\
\text { Recycled }\end{array}$ \\
\hline \hline Steel & 17 & - & - \\
Copper & 5 & 5 & 2.5 \\
Aluminium & 3 & 20 & 10 \\
Plastics & 11 & 11 & - \\
Glass & 46 & 46 & 23 \\
Wood & 18 & 18 & - \\
\hline Total & 100 & 100 & $\mathbf{3 5 . 5}$ \\
\hline *Bill of Materials of current product are taken from [14]. & &
\end{tabular}

The pertinent changes for these modifications on the design phase act upon the architecture of the product (step 5), given that the material contents have changed, but no functional or conceptual characteristics have, such an adjustment belongs to the criticality class number 2 (step 6), with a significant success probability of the design. The decision is made and respective process changes (step 7) are adjusted within the manufacturing phase.

\section{Conclusion}

Sustainability in the industrial context is a matter of practical implementations with the aim of minimizing its counter impact on the environment and society. Our work focuses in the impact of products at their End-of-Life (EOL) phase. Traditionally, in practice, the EOL of the product is determined using what we call a "forward approach": from the product characteristics to the respective EOL practice decision (i.e. reuse, remanufacture, recycle, and dispose), which in the end is taken in terms of profitability. The methodology proposed provides a way to assess the impact on 
product design that ultimately helps on deciding the product characteristics required for a desired EOL practice. For instance, a company wants to sell a product to be at the end of its life $\mathrm{x} \%$ recyclable, what impact on the design of the product would this entail? We transfer these considerations to the industrial design context. The result allows designers to identify the impact of these requirements and assist during the product development process.

Acknowledgments. The paper is the results of a research which is partially funded the EC project LeanPPD Lean Product and Process Development NMP-LA 2008214090 .

\section{References}

1. Huisman, J.: The QWERTY/EE Concept Quantifying Reciclability and Eco-Efficiency for End-of-life Treatment of Consumer Electronic Products. PhD thesis, Delft TU, The Netherlands (2003)

2. Lund, R.T., Hauser, W.: The Remanufacturing Industry: Anatomy of a Giant. Department of Manufacturing Engineering, Boston University, Massachusetts (2003)

3. EEA (European Environmental Agency) Glossary. Obtained through the Internet, http: / / glossary . eea. europa. eu / (accessed on July 2009)

4. EU Directive 2002/96/EC on Waste Electrical and Electronic Equipment (WEEE) (2002), http://ec.europa.eu/environment/waste/weee/index_en.htm (accessed on July 2009)

5. EU Directive 2000/53/EC on End-of-Life Vehicle (2002), http://ec.europa.eu/environment/waste/elv_index.htm (accessed on July 2009)

6. EU Directive 2002/95/EC on RoHS (Restriction of Hazardous Substances) (2002), http://ec.europa.eu/environment/waste/weee/index_en.htm (accessed on July 2009)

7. Ulrich, K.T., Eppinger, S.D.: Product design and development, 4th edn. McGraw-Hill Higher Education, Boston (2008)

8. Sobek, D.K.: Transitions: From Conceptual Ideas to Detail Design. In: Proceedings of the 2005 American Society for Engineering Education Annual Conference \& Exposition (2005)

9. Dym, C.L., Little, P.: Engineering Design: A Project-Based Introduction. John Wiley \& Sons, New York (2000)

10. Pahl, G., Beitz, W.: Engineering Design: A Systematic Approach. Springer, New York (2001)

11. Sperandio, S., Robin, V., Girard, P.: Management of risk caused by domino effect resulting from design system dysfunctions. In: Joint ESREL 2008 and 17th SRA-EUROPE Conference, September 22-25. Universidad Politecnica de Valencia, Spain (2008)

12. Dahmus, J., Gutowski, T.: What Gets Recycled: An Information Theory Based Model of Product Recycling. Environmental Science and Technology (41), 7543-7550 (2007)

13. Ashby, M.F.: Materials and the Environment: Eco-informed Material Choice. Elsevier Science \& Technology/Butterworth-Heinemann

14. Truttmann, N., Rechberger, H.: Contribution to resource conservation by reuse of electronical and electronic household appliances. Resource Conservation and Recycling 48(3), 249-261 (2006) 